Revue

Revue de l'histoire des religions

de Ihistoire des religions

Étienne ANHEIM, Clément VI au travail. Lire, écrire, prêcher au XIV siècle

Paris, Publications de la Sorbonne, 2014

\title{
Marie Lezowski
}

\section{OpenEdition}

\section{Journals}

Édition électronique

URL : http://journals.openedition.org/rhr/8782

DOI : $10.4000 /$ rhr.8782

ISSN : 2105-2573

\section{Éditeur}

Armand Colin

\section{Édition imprimée}

Date de publication : 1 septembre 2017

Pagination : 550-552

ISBN : 978-2-200-93127-8

ISSN : 0035-1423

Référence électronique

Marie Lezowski, «Étienne AnHeım, Clément VI au travail. Lire, écrire, prêcher au xı siècle », Revue de I'histoire des religions [En ligne], 3 | 2017, mis en ligne le 01 septembre 2017, consulté le 07 janvier 2021. URL : http://journals.openedition.org/rhr/8782 ; DOI : https://doi.org/10.4000/rhr.8782

Ce document a été généré automatiquement le 7 janvier 2021.

Tous droits réservés 


\title{
Étienne ANHEIM, Clément VI au travail. Lire, écrire, prêcher au XIV siècle
}

Paris, Publications de la Sorbonne, 2014

\author{
Marie Lezowski
}

\section{RÉFÉRENCE}

Étienne ANHEIM, Clément VI au travail. Lire, écrire, prêcher au XIV viècle, Paris, Publications de la Sorbonne, 2014, 24 cm, 406 p., 30 €, ISBN 2-85944-875-6.

1 Pierre Roger, élu pape en 1342 sous le nom de Clément VI (1290/1-1352), est surtout fameux pour les critiques dont l'accablent Pétrarque et d'autres détracteurs de la monarchie pontificale. Quand la légende noire du pape avignonnais tyrannique, népotiste et débauché s'impose à l'historien, la tentation de la réhabilitation est grande. Dans ce livre issu de sa thèse, Étienne Anheim adopte un tout autre parti. Après un résumé décapant des échecs diplomatiques de son anti-héros (p.14-16), l'auteur prend Pétrarque au mot. Qu'est-ce que le goût des apparences pour un souverain pontife du début du XIV ${ }^{\mathrm{e}}$ siècle? Le legs le plus visible de cette "politique de représentation » (p. 71) est le chantier du Palais des Papes, que l'auteur a aussi étudié dans sa thèse et dont il réserve la publication pour un prochain livre. Le second volet, objet de la présente étude, est le plus ardu à étudier : ce sont les trésors de rhétorique que Pierre Roger déploie le plus souvent en latin, et qui lui valent la réputation de rhéteur hors pair. « Le fond, chez lui, réside d'abord dans la forme » (p. 130) : quelle est exactement cette marque stylistique imposée par Clément VI au magistère pontifical ?

2 La question parcourt le livre, mené en quatre parties et quatorze chapitres. En préambule, l'auteur introduit au personnage par une série de témoignages, à charge et à décharge, avant de résumer sa trajectoire, de donner une vue de sa bibliothèque et de ses œuvres (chap. 1 à 3). Vient ensuite le cœur du travail de Pierre Roger quand il s'attelle à la composition d'un sermon: sélectionner des autorités, annoter des manuscrits et copier des originaux, ajuster ses compositions aux contraintes du sermo 
modernus (chap. 4 à 6). Dans les troisième et quatrième temps, É. Anheim fait le lien entre le travail de la forme et les thèmes majeurs de sa prédication : le dialogue entre théologie et philosophie naturelle (chap. 7), la défense et illustration de la monarchie pontificale (chap. 8 à 10), la réforme de l'Église enfin, abordée par plusieurs sujets brûlants de son pontificat: la critique morale des clercs, le jubilé de 1350, la canonisation d'Yves de Tréguier et le contrôle de l'université de Paris (chap. 11 à 14). Cet exposé succinct met en évidence la grande richesse des sujets explorés dans le livre, tous étayés par une réflexion approfondie sur les pratiques politiques de l'éloquence.

Sur un plan théorique, comme le souligne l'auteur à de multiples reprises, Clément VI n'invente rien. Fidèle aux idéaux théocratiques des $\mathrm{XII}^{\mathrm{e}}$ et $\mathrm{XIII}^{\mathrm{e}}$ siècles, il défend une conception monarchique et universelle de l'Église, ce que signale la citation fréquente de Bernard de Clairvaux dans ses sermons (chap.4). Tout au plus remarque-t-on la promotion originale de la figure de saint Jean. De cette figure du Verbe, moins directement liée à la ville de Rome que celle de Pierre (donc opportune en contexte avignonnais), Clément VI célèbre l'intelligence, le savoir et l'éloquence. Il brosse ainsi un portrait de l'évangéliste qui lui ressemble (chap. 10). Au service de cette pensée traditionnelle, l'art oratoire de Pierre Roger réside dans l'exploitation de schémas éprouvés (chap.6). Ses sermons font jouer tous les ressorts du sermo modernus : correspondance des sens et des sons dans l'exposé des "distinctions", variété des citations, primat de l'exposé sur la narration. Sur ce canevas bien rodé, la signature de sa prédication est l'accumulation des effets, exploités à un très haut degré d'intensité. Clément VI sait aussi ruser avec les règles du genre : l'introduction, moins contrainte que le développement, sert les besoins spécifiques de l'exposé. Forme et fond se répondent, pour porter la tradition scolastique à un point de perfection et offrir aux conceptions théocratiques l'éclat d'une prose musicale.

Cependant, Clément VI ne peut plus défendre la plénitude du magistère pontifical avec les armes rhétoriques des $\mathrm{XII}^{\mathrm{e}}$ et XIII ${ }^{\mathrm{e}}$ siècles. Face aux assauts conjugués des pouvoirs princiers et du nominalisme, il accomplit une série de "déplacements " savants et stylistiques. Par ce mot, préféré à celui d'«innovation», É. Anheim refuse la qualification "intermédiaire » de ses sermons, qui repose sur l'idée d'un passage progressif du sermon scolastique au sermon humaniste (p. 205). Les plus importants « déplacements » identifiés concernent la liberté des introductions, déjà signalée, et le recours accru aux auteurs dans le texte, en particulier à Aristote.

Pierre Roger fréquente assidûment les auteurs cités dans ses sermons, ce que l'on sait par les annotations marginales de ses manuscrits (chap. 5). Certes, il possède dans sa bibliothèque de nombreux recueils de citations prêtes à l'emploi. Mais il a lu et annoté de près les auteurs de prédilection dans ses prêches, tels Aristote, Augustin et Bernard. Ce point est l'occasion d'une réflexion très stimulante sur la définition d'un texte original dans une œuvre construite à partir de citations (p.169-178). Aristote est surtout cité d'après des florilèges, ce qui n'empêche pas Clément VI d'avoir une connaissance de première main de son œuvre, acquise pendant ses années universitaires. Entre l'original et le recueil, il faut faire la part des souvenirs de lecture plus ou moins conscients, réactivés par le florilège. C'est pourquoi la recherche génétique donne des résultats souvent décevants (p. 179). À tout le moins, un recueil de 1329-1330 atteste sa connaissance directe des écrits de Bernard.

Qu'elle provienne du texte original ou d'un florilège, l'inspiration aristotélicienne de nombreux sermons est avérée. Ce faisant, Clément VI s'approprie la référence par 
excellence des adversaires de la monarchie pontificale. À nouveau, souligne É. Anheim, cette nouveauté est relative; elle s'inscrit dans la continuité de la synthèse intellectuelle voulue par Jean XXII, qui réunit les auteurs d'inspiration grégorienne et Aristote dans la défense du pouvoir pontifical (p. 242). D'Aristote, Clément VI retient d'abord la morale et la philosophie naturelle, qu'il emploie dans des distinctions sur le mouvement de l'âme (chap.7). Mais il prend très rarement position sur des sujets spéculatifs. L'œuvre d'Aristote est surtout mobilisée à des fins théologico-politiques, y compris quand elle n'est pas citée explicitement. Par exemple, un important «soustexte » de la définition de la prudentia est le commentaire de l'Éthique à Nicomaque par Averroès, que Pierre Roger possède et annote (chap. 8, p. 247-248). La question centrale de l'aristotélisme politique, est, regrettons-le, peut-être traitée un peu rapidement dans le chapitre 8, en particulier la réponse apportée à Marsile de Padoue (p. 241).

7 Enfin, couronnement du livre, l'auteur en vient à l'exposé des morceaux de bravoure de cette éloquence, quand clément VI prêche la nécessaire réforme des clercs et les principales réalisations de son pontificat. Conscient, comme tous ses contemporains, de la crise de l'Église, le pape a des mots durs pour l'appétit de pouvoir des clercs. Ses critiques cinglantes ne sont guère éloignées de celles de Pétrarque à son encontre ; mais il est difficile de trancher sur la portée de ces discours (chap. 11). En revanche, la parole du pape est directement efficace, quand il proclame le jubilé pour 1350, qu'il porte un saint sur les autels et qu'il condamne des doctrines dangereuses. La rhétorique de Clément VI fait merveille pour expliciter le sens théologique du jubilé institué par Boniface VIII (chap. 12) : c'est lui qui introduit l'idée essentielle du trésor de l'Église, dans la bulle Unigenitus (1349). C'est lui, aussi, qui proclame en 1347 la canonisation d'Yves de Tréguier, et qui esquisse ainsi la figure moderne du prêtre héroïque dans le quotidien de la pastorale. Il expose cette conception neuve de la sainteté sous la forme d'une question quodlibétique (chap. 13). Il est vrai que le procès en canonisation a été voulu par Jean XXII, tout comme la condamnation des doctrines nominalistes à l'université, formalisée par la bulle de 1346 (chap. 14). Sur ces trois dossiers, l'auteur vérifie l'attachement de Clément VI aux leçons de Boniface VIII et de Jean XXII, et son talent particulier à expliciter avec brio des théories formulées avant lui.

8 La mécanique des sermons étant parfaitement élucidée, leurs effets sur le gouvernement de l'Église sont plus délicats à évaluer. Tout en renforçant l'emprise fiscale et territoriale du pape sur ses États, Clément VI n'enraye pas la faillite spirituelle $\mathrm{du}$ magistère pontifical. L'auteur n'entend pas revenir sur ce constat, posé dès l'introduction. Mais alors comment mesurer l'efficacité du discours, qui est l'horizon constant de toutes ces recherches de style ? Peut-être y aurait-il eu matière à prolonger les réflexions introductives sur le "charisme " de Clément VI, qui attire les hommes à lui et rend sa seule présence désirable (p.60), en donnant plus de détails sur les circonstances de telle ou telle performance oratoire et sur leur réception immédiate. La publication à venir du chantier du Palais des Papes apportera sans nul doute de nombreux éléments sur le théâtre de ces représentations. En se concentrant ici sur la prédication, É. Anheim accomplit le tour de force de rendre sensibles les séductions d'une rhétorique qui nous sont devenues totalement hermétiques. Le livre achevé, on relit en connaissance la galerie de portraits du préambule et on comprend comment ce maitre de l'effet de style a pu susciter fascination ou aversion parmi les lettrés de son temps. 


\section{AUTEURS}

MARIE LEZOWSKI

Université d'Angers - Centre de recherches historiques de l'Ouest. 